\title{
BMJ Open Maintenance therapy with proton pump inhibitors and risk of gastric cancer: a nationwide population-based cohort study in Sweden
}

\author{
Nele Brusselaers, ${ }^{1}$ Karl Wahlin, ${ }^{2}$ Lars Engstrand, ${ }^{3}$ Jesper Lagergren ${ }^{2,4}$
}

To cite: Brusselaers N, Wahlin K, Engstrand L, et al. Maintenance therapy with proton pump inhibitors and risk of gastric cancer: a nationwide population-based cohort study in Sweden. BMJ Open 2017;7:e017739. doi:10.1136/ bmjopen-2017-017739

- Prepublication history and additional material for this paper are available online. To view these files, please visit the journal online (http://dx.doi. org/10.1136/bmjopen-2017017739).

Received 15 May 2017 Revised 31 August 2017 Accepted 5 October 2017

\section{CrossMark}

${ }^{1}$ Department of Microbiology, Tumor and Cell Biology, Science for Life Laboratory, Karolinska Institutet, Stockholm, Sweden ${ }^{2}$ Department of Molecular Medicine and Surgery, Upper Gastrointestinal Surgery, Karolinska Institutet, Karolinska University Hospital, Stockholm, Sweden

${ }^{3}$ Department of Microbiology, Tumor and Cell Biology, Science for Life Laboratory, Karolinska Institutet, Stockholm, Sweden ${ }^{4}$ Division of Cancer Studies, King's College London, London, UK

Correspondence to Dr Nele Brusselaers; nele.brusselaers@ki.se

\section{ABSTRACT}

Objective Proton pump inhibitors (PPIs) are among the most commonly prescribed drugs. Concerns have been raised about a potentially increased risk of gastric cancer following long-term use. Our aim is to assess the risk of gastric cancer associated with PPI use, taking into account underlying indications.

Design This is a population-based cohort study. Standardised incidence ratios (SIRs) and $95 \%$ Cls were calculated to compare the risk of gastric cancer among long-term PPI users with the corresponding background population, while taking confounding by indication into account.

Setting Population-based study in Sweden (2005-2012). Participants This study included virtually all adults residing in Sweden exposed to maintenance therapy with PPIs.

Exposure/Intervention Maintenance use of PPIs, defined as at least 180 days during the study period. Maintenance use of histamine 2 receptor antagonist was evaluated for comparison reasons.

Outcome measures Gastric cancer (cardia and noncardia), and subgroup analysis for gastric adenocarcinoma, as defined by the Swedish Cancer Registry.

Results Among 797067 individuals on maintenance PPI therapy, the SIR of gastric cancer was over threefold increased (SIR=3.38, 95\% $\mathrm{Cl} 3.23$ to 3.53). Increased SIRs were found in both sexes and all age groups, but were especially increased among PPI users younger than 40 years ( $\mathrm{SIR}=22.76,95 \% \mathrm{Cl} 15.94$ to 31.52). Increased SIRs were found for each indication studied, including those without an association with gastric cancer, for example, gastro-oesophageal reflux (SIR=3.04, $95 \% \mathrm{Cl}$ 2.80 to 3.31 ), and those with a supposedly decreased risk, for example, aspirin users $(\mathrm{SIR}=1.93,95 \% \mathrm{Cl}$ 1.70 to 2.18). The association was similar for cardia and non-cardia gastric cancer. Analyses restricted to adenocarcinoma showed similar results to those for all gastric cancers. Long-term users of histamine 2 receptor antagonists, which have the same indications as PPIs, were not at any increased risk.

Conclusions Long-term PPI use might be an independent risk factor for gastric cancer. This challenges broad maintenance PPI therapy, particularly if the indication is weak.
Strengths and limitations of this study

- This is a population-based and nationwide design based on contemporary use of proton pump inhibitors (PPIS), resulting in sufficient power to assess underlying indications (to assess confounding by indication).

- To our knowledge, this is the largest study to date assessing the association between PPIs and gastric cancer.

- The findings are standardised for age and sex, which are often described the major confounding factors in epidemiological studies, and calendar time. Yet other confounders could not be taken into account because the information was not available for the background population.

- Exposure information is based on the Swedish Prescribed Drug Registry, which is initiated in July 2005 and has a complete nationwide coverage.

- Although this study provides some evidence for an association between PPI use and gastric cancer beyond gastrointestinal indications of use, conclusions considering causality can never be drawn based on a single study.

\section{INTRODUCTION}

Proton pump inhibitors (PPIs), introduced in the 1980 s, are potent gastric acid suppressors that reduce gastric acidity. ${ }^{1-3}$ PPIs are among the most prescribed drugs globally, ${ }^{4}$ used for healing peptic ulcers, counteracting gastro-oesophageal reflux, eradicating Helicobacter pylori (in combination with antibiotics) and preventing primary or recurrent peptic ulcers, for example, in individuals exposed to aspirin or other non-steroidal anti-inflammatory drugs (NSAIDs) or with Zollinger-Ellison syndrome (a gastrin-secreting pancreatic tumour). However, it has been suggested that long-term PPI use increases the risk of premalignant gastric lesions (eg, polyps, atrophy and metaplasia) and gastric cancer. ${ }^{256}$ Gastric acid secretion blockage may disrupt the gastric microbiome, 
interfere with nitrosamine formation, cause chronic atrophic gastritis and increase gastrin serum levels, which can all contribute to gastric cancer development. ${ }^{2578}$ The effect of PPI use on the gut microbiome may even be more prominent than the effects of antibiotics. ${ }^{9}$ Among three recent meta-analyses on the topic, one found no association between long-term PPI use and premalignant gastric lesions, based on six randomised controlled trials (1789 patients in total). ${ }^{2}$ The second included an additional trial (2343 patients in total) and found no evidence of gastric tumour development in PPI users with atrophy or intestinal metaplasia, while an increased risk of gastric hyperplasia was indicated. ${ }^{6}$ The third, based on 11 observational studies (94558 participants), reported a $40 \%$ increase of gastric cancer among PPI users. ${ }^{5}$ However, the impact of confounding by indication remains unknown. The present study aimed to assess the risk of gastric cancer in long-term PPI users in a population-based design, while taking confounding by indication for such treatment into account. For comparison reasons, use of histamine 2 receptor antagonists (H2RAs), which are used for similar indications as PPIs, was also studied.

\section{METHODS \\ Design}

This was a nationwide Swedish population-based cohort study designed to examine the risk of gastric cancer in individuals exposed to maintenance therapy with PPIs (and to maintenance use of H2RAs), compared with the Swedish background population of the same sex, age and calendar period (7.1-7.6 million adults) ${ }^{10}$

Only adults (at least 18 years) without a history of any cancer were included. The participants were followed up from the first prescription of a PPI (or H2RA) during the period 1 July 2005-31 December 2012. The data were derived from high-quality and nationwide Swedish registries, and information on individuals was linked between the registries by means of the unique Swedish personal identity number. ${ }^{11}$ The source cohort included all Swedish residents who received at least one dispensed prescription of commonly prescribed drugs (listed in online supplementary appendix 1) between 1 July 2005 and 31 December 2014 (with follow-up for cancer until 31 December 2012). Informed consent was not required.

\section{Patient involvement}

The Swedish patient organisation for cancer of the oesophagus, stomach, liver and pancreas was involved in supporting the present study (www.palema.org). The development of the research question and outcome measures were informed by patients' priorities, experiences and preferences. The results will be disseminated to study participants by means of patient organisations. Patients are thanked in the acknowledgements.

\section{Exposure}

The study exposure was maintenance therapy with a PPI (or an H2RA) according to the Swedish Prescribed Drug Registry, defined as a cumulative defined daily dose (DDD) of at least 6 months ( $\geq 180$ days) during the study period (before a potential cancer diagnosis). The DDD was the average maintenance dose per day for a drug used for its main indication in adults, which follows the WHO definition. This cumulative DDD was estimated by adding the DDD per package, which takes both the potency and the quantity of the drug into account, and is therefore a proxy for the duration of the exposure. The Anatomical Therapeutic Chemical classification system (ATC) was used to identify codes representing PPIs (code A02BC) and H2RAs (code A02BA). The participants were divided into three mutually exclusive exposure groups: (1) PPI users ( $\geq 180$ days on PPIs and $<180$ days on H2RAs); (2) H2RA users ( $\geq 180$ days on H2RAs and $<180$ days on PPIs); and (3) PPI and H2RA users ( $\geq 180$ days on PPIs and $\geq 180$ days on H2RAs). These medications were also available over the counter in Sweden, but only in small packages and at a much higher price per dose. ${ }^{12}$ Thus, maintenance users had their medication prescribed and were therefore included in this study.

\section{Outcome}

The main outcome was a first episode of any gastric cancer according to the Swedish Cancer Registry. Gastric cancer was defined by the diagnosis codes C16.0 (cardia) and C16.1-C16.9 (non-cardia) in the 10th version of the International Classification of Diseases (ICD), and adenocarcinoma (dominating histological type) was defined by the histology code 096.

\section{Confounders}

Age, sex and calendar period were adjusted for in the design. Confounding by indication was evaluated by analysing indications for PPI use separately (see online supplementary appendix 2 for ICD and ATC codes): gastro-oesophageal reflux disease, Barrett's oesophagus, peptic ulcer disease, Zollinger-Ellison syndrome, gastroduodenitis, dyspepsia/disruption of gastric function, $H$. pylori infection, $H$. pylori eradication (combined with $H$. pylori infection in the analyses), and maintenance use ( $\geq 180$ days) of aspirin or other NSAIDs.

\section{Data sources}

Four nationwide Swedish registries, all maintained by the governmental National Board of Health and Welfare, provided data for the study.

The Swedish Prescribed Drug Registry started on 1 July 2005, and includes all drugs prescribed and dispensed in Sweden. Information from these prescriptions is transferred for registration monthly. ${ }^{13}$ This registry is highly complete (patient identity data are missing in $<0.3 \%$ of all items $),{ }^{13}$ and was used to collect data on type of medication, dates of prescribing and dispensing, and DDD per package. 
The Swedish Cancer Registry has at least a 96\% complete registration of all cancers in Sweden since 1958, ${ }^{14}$ with $98 \%$ completeness for gastric cancer. ${ }^{1516}$ This registry was used to identify gastric cancer cases among the cohort members and the corresponding background population (exact annual numbers were available for the used age and sex categories), and to exclude individuals with a history of any cancer.

The Swedish Patient Registry has a full nationwide coverage for all diagnoses from 1987. ${ }^{11}$ The registration of outpatient specialist care is nationwide since 2001. This registry was used to collect information on indications for PPI use.

The Swedish Causes of Death Registry has 100\% completeness for recording of dates of death since 1952. ${ }^{17}$ This registry was used to collect date of death.

\section{Statistical analyses}

All analyses were conducted according to a preplanned protocol. The risk of gastric cancer was compared between the exposed cohort and the entire Swedish background population of the same sex (male or female), age group (categorised as 18-39, 40-49, 50-59, 60-69 or $\geq 70$ years) and calendar period (2005-2006, 2007-2009 or 2010-2012). Standardised incidence ratios (SIRs) and $95 \%$ CIs were calculated by dividing the observed number of gastric cancer cases with the expected number, accounting for changes in age and calendar categories. ${ }^{18}$ The expected numbers were derived from the Swedish Cancer Registry and Statistics Sweden. ${ }^{10}$ Follow-up time was calculated from the dispense date of the first prescription of PPI (or H2RA) within the study period, until death, any cancer or end of the study period (31 December 2012), whichever occurred first. Subgroup analyses were stratified for sex and age. Stratified analyses were performed for each indication whenever at least 10000 exposed individuals were identified with this indication. To assess reverse causality (protopathic bias), a sensitivity analysis was conducted excluding all cancer cases occurring within 1 year of the start of the study. Duration of PPI use was estimated based on the total DDD per package prescribed before any cancer diagnosis, and was categorised into $<1.0$ year, $1.0-2.9$ years, $3.0-4.9$ years or $\geq 5$ years.

The attributable fraction (AF) and the population attributable fraction (PAF) were calculated to estimate the proportion of gastric cancer in PPI users and the total population, respectively (assuming causality). The following formulas were used: $\mathrm{AF}=(\mathrm{SIR}-1) / \mathrm{SIR}$ and $\mathrm{PAF}=\mathrm{p}(\mathrm{SIR}-1) /(\mathrm{p}(\mathrm{SIR}-1)+1)$, where $\mathrm{p}$ represents the prevalence of PPI maintenance use in the population (based on the population size in 2009). ${ }^{10}$ The $\chi^{2}$ test was used to calculate $\mathrm{p}$ values.

There were no missing data on exposures, outcomes, age, sex or calendar period. When no information was available for the indication for PPI use $(25.0 \%)$, the indication was considered absent.

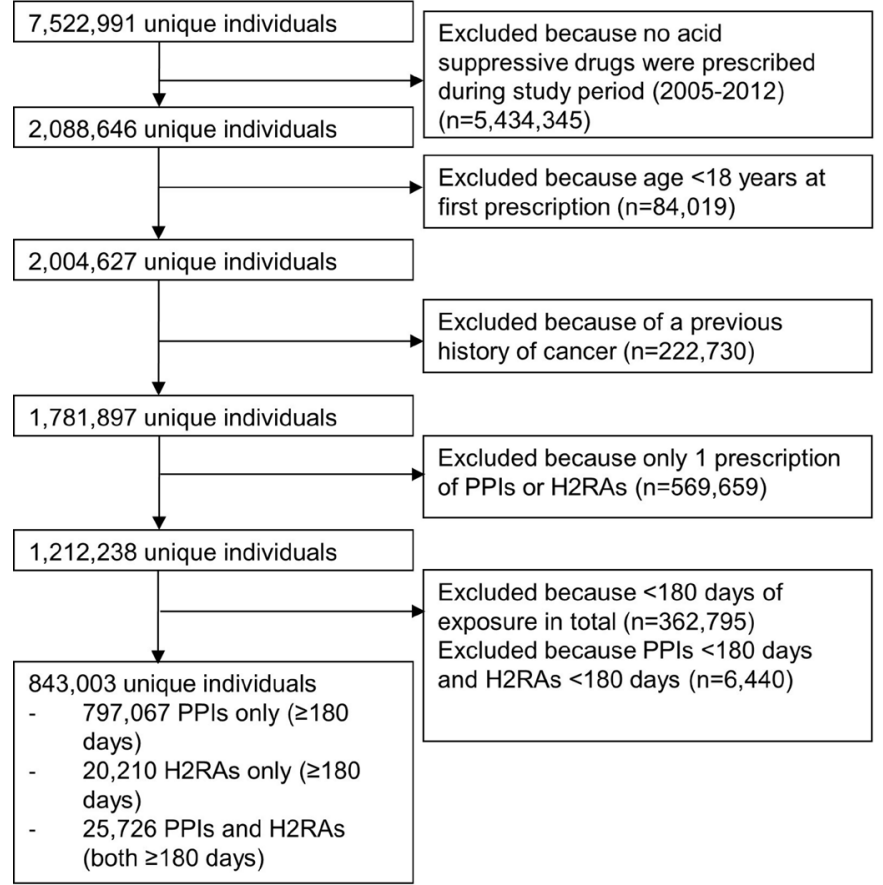

Figure 1 Flow chart of the construction of the cohort exposed to maintenance therapy with proton pump inhibitors (PPIs) and/or histamine 2 receptor antagonists (H2RAs).

\section{RESULTS}

\section{Study participants}

In total, 797067 individuals on maintenance PPI therapy were included in the exposed cohort, resulting in 3866836 person-years of follow-up (mean 4.9 years). An additional 20210 individuals had maintenance H2RA therapy, and 25726 had both PPI and H2RA maintenance therapy. Figure 1 presents how the study participants were selected, and table 1 shows their characteristics. Women constituted $58.5 \%$ of the PPI cohort, and a majority $(66.1 \%)$ was younger than 70 years. Maintenance therapy with aspirin $(34.8 \%)$ and NSAIDs $(30.4 \%)$ was the most common indication for maintenance PPI use, followed by gastro-oesophageal reflux $(25.3 \%)$, gastroduodenitis $(13.2 \%)$ and peptic ulcer $(10.0 \%)$. H. pylori was the indication in $7.3 \%$ of all participants, and dyspepsia in $5.5 \%$. Barrett's oesophagus and Zollinger-Ellison syndrome were rare indications $(<1 \%)$ and therefore not eligible for separate analysis. A third $(33.4 \%)$ of the participants had more than one of the listed indications, and were therefore included in more than one indication group. Overall mortality was slightly lower among PPI users $(17.3 \%)$ compared with H2RA maintenance users $(19.4 \%)(\mathrm{p}<0.001)$, while mortality in patients with gastric cancer did not differ significantly $(\mathrm{p}=0.782)$.

\section{PPI use and overall risk of gastric cancer}

Among all participants exposed to maintenance PPIs, $2219(0.28 \%)$ developed gastric cancer during follow-up. Of these, $1652(74.4 \%)$ had non-cardia gastric cancer and $1943(87.6 \%)$ had adenocarcinoma (table 1). Long-term PPI users were at more than a threefold increased SIR of 
Table 1 Descriptive characteristics of the study cohort exposed to maintenance therapy with proton pump inhibitors (PPIs) and/or histamine 2 receptor antagonists (H2RAs)

\begin{tabular}{|c|c|c|c|}
\hline & $\begin{array}{l}\text { PPIs only } \\
\mathrm{n}(\%)\end{array}$ & $\begin{array}{l}\text { H2RAs } \\
\text { only } \\
\text { n (\%) }\end{array}$ & $\begin{array}{l}\text { PPIs and } \\
\text { H2RAs } \\
\text { n (\%) }\end{array}$ \\
\hline Total & 797067 & 20210 & 25726 \\
\hline \multicolumn{4}{|l|}{ Sex } \\
\hline Men & $\begin{array}{l}330885 \\
(41.5)\end{array}$ & $8076(40.0)$ & 9778 (38.0) \\
\hline Women & $\begin{array}{l}466182 \\
(58.5)\end{array}$ & $\begin{array}{l}12134 \\
(60.0)\end{array}$ & $\begin{array}{l}15948 \\
(62.0)\end{array}$ \\
\hline \multicolumn{4}{|l|}{ Age (years) } \\
\hline$<40$ & 89231 (11.2) & $1885(9.3)$ & $1822(7.1)$ \\
\hline $40-49$ & $\begin{array}{l}104003 \\
(13.1)\end{array}$ & 2461 (12.2) & $3268(12.7)$ \\
\hline $50-59$ & $\begin{array}{l}155963 \\
(19.6)\end{array}$ & 3971 (19.7) & $5878(22.9)$ \\
\hline $60-69$ & $\begin{array}{l}177606 \\
(22.3)\end{array}$ & $4563(22.6)$ & $6354(24.7)$ \\
\hline$\geq 70$ & $\begin{array}{l}270264 \\
(33.9)\end{array}$ & 7330 (36.3) & $8404(32.7)$ \\
\hline \multicolumn{4}{|l|}{ Calendar period } \\
\hline 2005-2006 & $\begin{array}{l}446068 \\
(56.0)\end{array}$ & $\begin{array}{l}16550 \\
(81.9)\end{array}$ & $\begin{array}{l}23066 \\
(90.0)\end{array}$ \\
\hline 2007-2009 & $\begin{array}{l}222257 \\
(27.9)\end{array}$ & $2670(13.2)$ & $2304(9.0)$ \\
\hline 2010-2012 & $\begin{array}{l}128742 \\
(16.2)\end{array}$ & 990 (4.9) & $356(1.4)$ \\
\hline \multicolumn{4}{|l|}{ Indications } \\
\hline $\begin{array}{l}\text { Gastro- } \\
\text { oesophageal } \\
\text { reflux }\end{array}$ & $\begin{array}{l}201868 \\
(25.3)\end{array}$ & 2073 (10.3) & $6727(26.2)$ \\
\hline $\begin{array}{l}\text { Barrett's } \\
\text { oesophagus }\end{array}$ & $6044(0.8)$ & $17(0.1)$ & $172(0.7)$ \\
\hline Peptic ulcers & 79597 (10.0) & $1226(6.1)$ & 2633 (10.2) \\
\hline $\begin{array}{l}\text { Zollinger-Ellison } \\
\text { syndrome }\end{array}$ & $31(0.0)$ & $0(0.0)$ & $3(0.01)$ \\
\hline Gastroduodenitis & $\begin{array}{l}104955 \\
(13.2)\end{array}$ & $1321(6.5)$ & 3695 (14.4) \\
\hline Dyspepsia & $43901(5.5)$ & $649(3.2)$ & $1664(6.5)$ \\
\hline $\begin{array}{l}\text { Helicobacter } \\
\text { pylori }\end{array}$ & $58366(7.3)$ & $641(3.2)$ & $2041(7.9)$ \\
\hline $\begin{array}{l}\text { Long-term non- } \\
\text { steroidal anti- } \\
\text { inflammatory } \\
\text { drug use }\end{array}$ & $\begin{array}{l}241958 \\
(30.4)\end{array}$ & $5012(24.8)$ & $9628(37.4)$ \\
\hline $\begin{array}{l}\text { Long-term } \\
\text { aspirin use }\end{array}$ & $\begin{array}{l}277128 \\
(34.8)\end{array}$ & $6533(32.3)$ & 9929 (38.6) \\
\hline \multicolumn{4}{|l|}{ Number of indications } \\
\hline 0 & $\begin{array}{l}199608 \\
(25.0)\end{array}$ & 7919 (39.2) & $5402(21.0)$ \\
\hline
\end{tabular}

Continued
Table 1 Continued

\begin{tabular}{|c|c|c|c|}
\hline & $\begin{array}{l}\text { PPIs only } \\
\mathrm{n}(\%)\end{array}$ & $\begin{array}{l}\text { H2RAs } \\
\text { only } \\
n(\%)\end{array}$ & $\begin{array}{l}\text { PPIs and } \\
\text { H2RAs } \\
n(\%)\end{array}$ \\
\hline 1 & $\begin{array}{l}330027 \\
(41.4)\end{array}$ & $8487(42.0)$ & $\begin{array}{l}10320 \\
(40.1)\end{array}$ \\
\hline$\geq 2$ & $\begin{array}{l}267432 \\
(33.6)\end{array}$ & 3804 (18.8) & $\begin{array}{l}10004 \\
(38.9)\end{array}$ \\
\hline \multicolumn{4}{|l|}{ Gastric cancer } \\
\hline All & $2219(0.28)$ & $12(0.06)$ & $62(0.24)$ \\
\hline Adenocarcinoma & $1943(0.24)$ & $10(0.05)$ & $54(0.21)$ \\
\hline Cardia & $567(0.07)$ & $1(0.00)$ & $13(0.05)$ \\
\hline Non-cardia & $1652(0.21)$ & $11(0.05)$ & $49(0.19)$ \\
\hline \multicolumn{4}{|l|}{ Years of follow-up } \\
\hline Total & 3866836 & 116015 & 163519 \\
\hline Mean & 4.9 & 5.7 & 6.4 \\
\hline \multicolumn{4}{|c|}{$\begin{array}{l}\text { Cumulative defined daily dosages, estimated number of } \\
\text { days }\end{array}$} \\
\hline Median & 856 & 450 & 1741 \\
\hline IQR & $356-2102$ & 270-990 & $1043-2732$ \\
\hline \multicolumn{4}{|l|}{ Mortality } \\
\hline Total & $\begin{array}{l}137619 \\
(17.3)\end{array}$ & 3915 (19.4) & $3812(14.8)$ \\
\hline $\begin{array}{l}\text { In gastric cancer } \\
\text { cases }\end{array}$ & $1473(66.4)$ & $9(75.0)$ & 39 (62.9) \\
\hline
\end{tabular}

gastric cancer of any type (SIR=3.38, 95\% CI 3.25 to 3.53 ) and gastric adenocarcinoma ( $\mathrm{SIR}=3.38,95 \%$ CI 3.23 to 3.53) (table 2). After excluding early gastric cancers, the risk remained increased ( $\mathrm{SIR}=1.61,95 \%$ CI 1.51 to 1.71). The risk of gastric cancer was highest among individuals receiving PPI for shorter than 1 year ( $\mathrm{SIR}=12.82$, 95\% CI 12.19 to 13.47), but there was also evidence for an increased risk up to 3 years of PPI use, yet reduced risks for use over 5 years (table 3 ). The strength of association was similar for cardia (SIR=3.55, 95\% CI 3.27 to 3.86) and non-cardia gastric cancer (SIR=3.33, 95\% CI 3.17 to 3.50 ). The risk of gastric cancer was similar in men ( $\mathrm{SIR}=3.65$, $95 \%$ CI 3.45 to 3.85 ) and women (SIR=3.07, 95\% CI 2.87 to 3.28$)$. The SIR was higher in younger ages; PPI users younger than 40 years had SIR of 22.76 (95\% CI 15.94 to 31.52), while those who were at least 70 years old had SIR of 2.76 (95\% CI 2.61 to 2.92) (table 2). The subgroup analyses for sex and age showed similar results as the overall findings in separate analyses for gastric adenocarcinoma, as well as for cardia and non-cardia gastric cancer (table 2).

\section{PPI use and risk of gastric cancer stratified by indication}

The SIR of gastric cancer was increased in each of the 10 studied groups of indications for PPI therapy (table 4). The highest SIRs were found among participants exposed to indications with a known association with gastric cancer, that is, H. pylori and peptic ulcer. However, the 
Table 3 Standardised incidence ratios (SIRs) by estimated duration of use and $95 \%$ Cls of gastric cancer in all individuals exposed to proton pump inhibitors

\begin{tabular}{llc}
\hline Duration & Cases $(\mathbf{n}) /$ total & SIR $(\mathbf{9 5} \% \mathbf{C l})$ \\
\hline$<1.0$ year & 1552 & $12.82(12.19$ to 13.47$)$ \\
1.0-2.9years & 2193 & $2.19(1.98$ to 2.42$)$ \\
3.0-4.9years & 1098 & $1.10(0.91$ to 1.31$)$ \\
$\geq 5.0$ years & 153 & $0.61(0.52$ to 0.72$)$ \\
\hline
\end{tabular}

SIRs were also increased for indications without any such association. The SIR for gastric cancer was 3.04 (95\% CI 2.80 to 3.31) for gastro-oesophageal reflux. The SIRs were increased also for indications where a decreased risk of gastric cancer was expected. The SIR was 1.93 (95\% CI 1.70 to 2.18) among those using PPIs because of aspirin use without any other indication. The SIRs were generally similar for non-cardia gastric cancer. Regarding cardia cancer, higher SIRs than for gastric cancer were found for the indications gastro-oesophageal reflux and among those exposed to aspirin or other NSAIDs, while the associations for $H$. pylori and peptic ulcer were less strong (table 4).

\section{Attributable risk}

Of all 5823 patients with gastric cancer diagnosed during the study period, $38.1 \%$ occurred among maintenance PPI users. Based on the overall SIR of 3.38 and a prevalence of PPI use of $10.7 \%$ among adults, the AF among PPI users (AF) was $70.4 \%$, and $20.3 \%$ in the total population (PAF), assuming causality. Using the lowest SIR according to table $4 \quad(\mathrm{SIR}=1.41)$, the corresponding proportions were $29.1 \%(\mathrm{AF})$ and $4.2 \%$ (PAF), respectively. Among individuals younger than 40 , the prevalence of PPI use was $3.3 \%$, and $37.1 \%$ of all 97 gastric cancers occurred among PPI users, corresponding to AF of $95.6 \%$ and PAF of $41.8 \%$.

\section{Use of histamine 2 receptor blockers only or PPIs and} histamine 2 receptor blockers and risk of gastric cancer

There were 12 and 62 cases of gastric cancer among maintenance H2RAs users only and both H2RAs and PPIs, respectively. The risk of gastric cancer was not increased in the H2RA-only group ( $\mathrm{SIR}=0.57,95 \%$ CI 0.29 to 0.99 ), and was moderately increased in the group exposed to both PPIs and H2RAs (SIR=2.09, 95\% CI 1.61 to 2.69).

\section{DISCUSSION}

This study provides some evidence of an increased risk of gastric cancer among maintenance PPI users, including those who had PPI therapy for indications without any positive association with gastric cancer. Increased risks were found for both cardia and non-cardia gastric cancer, in both sexes and all age groups, although the risk was more pronounced in younger participants. 


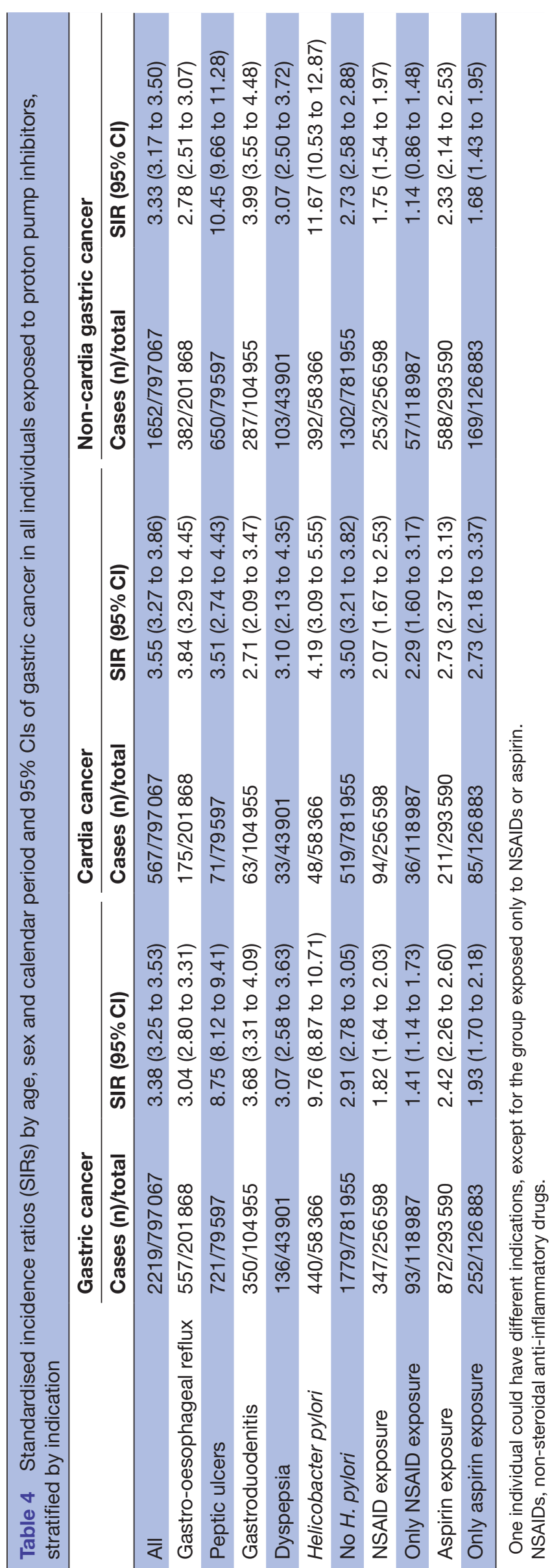

Strengths of the study include the nationwide and population-based design, the valid data on exposures, outcomes and indications for PPI use, and the large number of individuals exposed to maintenance treatment with PPIs. To our knowledge, this is the largest study to date on this topic, ${ }^{19}$ and the cohort allowed analyses of differences in associations between underlying indications.

The main problems of this study are confounding, especially by indication, and reverse causality. Confounding by indication has been investigated by looking at the different indication groups, including groups without no increased risk of gastric cancer. Unfortunately, we could not identify any underlying indication for $25 \%$ of the PPI users and $39 \%$ of the H2RA users. It is likely that clear indications were more readily recorded, while use for less rigorously diagnosed indications was more prone to be missing. This may indicate that PPI users had more severe symptoms than H2RA users, as also indicated by the higher proportion of PPI users presenting with multiple indications (34\% vs $19 \%$ ). Yet the lack of information on indication should not explain the associations for known indications-and those groups with no apparent risk factors should be less likely to have severe gastrointestinal symptoms. Therefore, it was unexpected to still see such increased risks of gastric cancer in those groups. Unfortunately, we lacked information about some potential confounders, for example, dietary factors, obesity, tobacco smoking and alcohol overconsumption, since these are not collected in the nationwide health registries. However, the lack of association between H2RAs and gastric cancer argues against bias from confounding or selection from lifestyle factors or any other unknown factors. Since H2RAs were used for similar indications as PPIs (yet clearly became less popular), the lack of association between H2RAs and gastric cancer supports that the association between PPI use and gastric cancer may be linked to the PPI medication per se. Yet PPIs clearly became the first choice of treatment for most indications for gastric acid suppression, with almost 40 times more PPI maintenance users than H2RA maintenance users in Sweden. The high prevalence of PPI maintenance use among adults ( $10.7 \%$ in Sweden) also means that the large majority with recognised risk factors for gastric cancer will have received PPI treatment at some point. This clearly hampers assessment of PPI use as an independent risk factor, and this may even be a larger problem in other study designs especially if indications of use cannot be assessed.

The problem of reverse causality, that is, individuals taking PPIs because of symptoms arising from an undetected cancer, should have been reduced by only including individuals with at least 180 days (6 months) of cumulative exposure before any cancer diagnosis. In addition, we excluded all individuals who had gastric cancer within a year after inclusion and also stratified the analyses by duration of use, which still showed increased risks (respectively $\mathrm{SIR}=1.61$ and $\mathrm{SIR}=2.19$ among those with an exposure duration between 1 and 3 years). These increased risks may not be entirely explained by reverse causality and detection bias alone-since most cases of gastric cancer are believed to be 
detected within 1 year after onset of symptoms. There are no significant waiting times or socioeconomic differences in access to endoscopy in Sweden, and no obvious differences were found between tumour stages (potential detection bias), ${ }^{20}$ or anatomical locations between the PPI-exposed cohort and the background population (online supplementary appendix 3 ).

The seemingly decreasing risk estimates with a longer duration of use are probably because PPI is beneficial for most individuals with known risk factors for cancer (eg, peptic ulcers, H. pylori), yet further research seems needed for those on maintenance therapy without gastrointestinal indications (eg, aspirin and NSAIDs users).

Although our follow-up should ideally have been longer, our maximal follow-up time is 7.5 years, which is remarkably longer than all studies included in the two meta-analyses assessing premalignant lesions based on randomised controlled trials (6-36 months as maximal follow-up) ${ }^{2} 6$ Only two smaller cohort studies had longer follow-up, ${ }^{1}{ }^{19}$ and these were included in the only meta-analysis evaluating gastric cancer risk based on observational studies. ${ }^{5}$ We also limited our study to maintenance use, defined as at least 180 days of exposure, which is a commonly used approach. ${ }^{6}$ Compliance and over-the-counter availability of some PPIs (esomeprazole, lansoprazole and pantoprazole-only in pharmacy, not in retail sale) may have resulted in different actual dosages. H2RAs were not available over the counter during the study period. Therefore, and because of lack of exposure data before the study period, we cannot be certain that the registered dosage reflects the actual dosage.

The increased risks of gastric cancer among individuals with $H$. pyloriand peptic ulcers were anticipated, since both these conditions are risk factors for gastric cancer, but the associations were stronger than expected, suggesting an additional aetiological role of the PPI use. Importantly, there was evidence of a substantially increased risk in individuals exposed to conditions not known to increase the risk of gastric cancer, including gastro-oesophageal reflux. Moreover, increased risks were found even among participants without any gastrointestinal indications who were exposed only to maintenance treatment with aspirin or other NSAIDs, although these drugs are expected to decrease the risk of gastric cancer. ${ }^{21} 22$

The higher risk of gastric cancer in the younger age group might be related to a recently described increase in atrophic gastritis in Sweden, as a potential consequence of the stabilising seroprevalence of $H$. pylori and increased prevalence of overweight and obesity. ${ }^{23}$ Increasing risks of gastric cancer in young populations have been described previously, in particular of the diffuse type of gastric adenocarcinoma. ${ }^{24}{ }^{25}$ Gastric symptoms in this group are also often overlooked, leading to a widespread (uncontrolled) use of PPIs. ${ }^{25}$ Additionally, gastric carcinogenesis may be accelerated in younger patients (who also have a higher likelihood of a family history of gastric cancer), ${ }^{26}$ which may in turn contribute to a higher vulnerability to PPI's potentially harmful effects. A further exploration into the presence and severity of gastrointestinal risk factors, age-specific effects and potential mechanistic pathways is warranted.

The difference in the association with gastric cancer following maintenance therapy with PPIs and H2RAs could be explained simply by the fact that PPIs are more potent than H2RAs in inhibiting acid secretion. ${ }^{27}$ PPIs block the gastric proton pumps, while H2RAs compete with histamine for the histamine 2 receptors. At recommended dosages, PPIs induce a more profound and prolonged acid inhabitation than H2RAs. Moreover, the acid inhibition of PPIs also increases over time, while the effects of H2RAs fade. ${ }^{27}$

There are several mechanisms that might explain an association between PPI use and gastric cancer. Already 30 years ago, animal studies showed that profound inhibition of gastric acid secretion in rodents induces gastric tumours, with secondary overstimulation (hypergastrinaemia) leading to enterochromaffin-like cell (ECL) hyperplasia as generally accepted mechanism of this carcinogenic effect. ${ }^{28}{ }^{29}$ ECL differentiation has also been described in human gastric carcinomas, particularly in the signet ring subtype. ${ }^{30}$ Histopathological changes occur due to the blockage of the normal gastric acid secretion, leading to hypergastrinaemia that might cause hyperproliferation of the gastric mucosa, chronic hypochlorhydria (reduction of hydrochloric acid in the gastric juice), chronic inflammation and disappearance of normal mucosal glands and their replacement by intestinal glands, and possible gastric atrophy. ${ }^{6}$ Long-term PPI use has also been linked to the development of fundic gland polyps. ${ }^{32}$ All these mucosal changes could promote gastric carcinogenesis. The blocked gastric acid secretion could decrease physiological defence mechanisms against pathogenic bacteria. ${ }^{78}$ Diarrhoea is, for example, a well-known side effect of PPI use, which is often due to infection with the bacteria Clostridium difficile, non-typhoid Salmonella species or Campylobacter jejuni. ${ }^{7}$ This reduced bacterial defence mechanism might, in the long term, result in chronic inflammation and eventually gastric cancer development. Decreased gastric acidity may also result in increased bacterial colonisation, including non-gastric micro-organisms, and a greater number of bacteria that produce nitrosamines, which are well-established carcinogens of the gastric mucosa. ${ }^{53}$ The impact of these proposed underlying mechanisms may also be person-dependent and time-dependent, which could explain why PPIs are seemingly more harmful in, for example, the younger age groups.

The results of a single study, even of this size, cannot determine causality. Yet the effect size, consistency across indications (especially those not associated with an increased risk of gastric cancer), lack of association with H2RAs and plausible carcinogenic mechanisms mean that maintenance PPI use cannot be dismissed as a potentially independent risk factor for gastric cancer. A higher awareness for gastric cancer could potentially be considered in maintenance users of PPI, especially if known underlying risk factors are present. Thus, these findings 
need confirmation in future investigations, especially considering the generalisability of the results to populations with higher incidence of gastric cancer or other distribution of risk factors.

To conclude, this large and population-based cohort study provides evidence of a substantially increased risk of gastric cancer following maintenance use of PPIs per se. The consistency across sexes, age groups and indication groups, including indications that do not increase the risk of gastric cancer, supports the overall finding. If confirmed in further research, especially among those without gastrointestinal risk factors, these findings challenge a broad use of long-term PPI use, particularly for conditions where the indication is weak.

Acknowledgements We are grateful to all thousands of patients, physicians and healthcare staff members who contributed to the data collection, and to the Swedish National Board of Health and Welfare, which collected the data.

Contributors NB had full access to all the data in the study and takes responsibility for the integrity of the data and the accuracy of the data analysis. NB conducted and is responsible for the data analysis. Everyone who contributed significantly to the work is listed as coauthor. Study concept and design: all authors. Acquisition of data: NB and JL. Data collection and preparation for analyses: NB and JL. Analysis and interpretation of data: all authors. Drafting of the manuscript: NB. Critical revision of the manuscript for important intellectual content: all authors. Statistical analysis: NB and KW. Obtained funding: JL and NB.

Funding The work was supported by the Swedish Research Council (8392008-7496), Swedish Cancer Society (CAN 2015/460), the Karolinska Institutet Distinguished Professor Award to JL (D-02418/2010) and SF0 Epidemiology (Young Scholar Grant to NB).

Competing interests None declared.

Ethics approval The study was approved by the Regional Ethical Review Board in Stockholm (2014/1291-31/4).

Provenance and peer review Not commissioned; externally peer reviewed.

Data sharing statement We are willing to share data upon request after ethical approval has been approved by the relevant committee and the governmental agencies that maintain the data.

Open Access This is an Open Access article distributed in accordance with the Creative Commons Attribution Non Commercial (CC BY-NC 4.0) license, which permits others to distribute, remix, adapt, build upon this work non-commercially, and license their derivative works on different terms, provided the original work is properly cited and the use is non-commercial. See: http://creativecommons.org/ licenses/by-nc/4.0/

(C) Article author(s) (or their employer(s) unless otherwise stated in the text of the article) 2017. All rights reserved. No commercial use is permitted unless otherwise expressly granted.

\section{REFERENCES}

1. Møller $\mathrm{H}$, Nissen A, Mosbech J. Use of cimetidine and other peptic ulcer drugs in Denmark 1977-1990 with analysis of the risk of gastric cancer among cimetidine users. Gut 1992;33:1166-9.

2. Eslami L, Nasseri-Moghaddam S. Meta-analyses: does long-term PPI use increase the risk of gastric premalignant lesions? Arch Iran Med 2013;16:449-58.

3. Shin JM, Sachs G. Pharmacology of proton pump inhibitors. Curr Gastroenterol Rep 2008;10:528-34.

4. The World Medicines Situation (WMS) 2011. Pharmaceutical concumption - Annex 4 Top 5 medicine classes by volume and country income category.

5. Ahn JS, Eom CS, Jeon CY, et al. Acid suppressive drugs and gastric cancer: a meta-analysis of observational studies. World $\mathrm{J}$ Gastroenterol 2013;19:2560-8.
6. Song H, Zhu J, Lu D. Long-term proton pump inhibitor (PPI) use and the development of gastric pre-malignant lesions. Cochrane Database Syst Rev 2014;12:CD010623.

7. Canani RB, Terrin G. Gastric acidity inhibitors and the risk of intestinal infections. Curr Opin Gastroenterol 2010;26:31-5.

8. Seto CT, Jeraldo P, Orenstein R, et al. Prolonged use of a proton pump inhibitor reduces microbial diversity: implications for Clostridium difficile susceptibility. Microbiome 2014;2:42.

9. Imhann F, Bonder MJ, Vich Vila A, et al. Proton pump inhibitors affect the gut microbiome. Gut 2016;65:740-8.

10. Statistics Sweden. Statistical database population statistics. Available from. http://www.statistikdatabasen.scb.se/http://www. statistikdatabasen.scb.se/ (accessed 06 Apr 2016).

11. Ludvigsson JF, Andersson E, Ekbom A, et al. External review and validation of the Swedish national inpatient register. BMC Public Health 2011;11:450.

12 . FASS (Farmacevtiska specialiteter i Sverige/ Farmaceutical specialities in Sweden) [Internet]. 2015 (cited Nov 2016). Available from: www.fass.se

13. Wettermark B, Hammar N, Fored CM, et al. The new Swedish Prescribed Drug Register--opportunities for pharmacoepidemiological research and experience from the first six months. Pharmacoepidemiol Drug Saf 2007:16:726-35.

14. Barlow L, Westergren K, Holmberg L, et al. The completeness of the Swedish Cancer Register: a sample survey for year 1998. Acta Oncol 2009;48:27-33.

15. Lindblad M, Ye W, Lindgren A, et al. Disparities in the classification of esophageal and cardia adenocarcinomas and their influence on reported incidence rates. Ann Surg 2006;243:479-85.

16. Ekström AM, Signorello LB, Hansson LE, et al. Evaluating gastric cancer misclassification: a potential explanation for the rise in cardia cancer incidence. J Natl Cancer Inst 1999;91:786-90.

17. The National Board of Health and Welfare,Sweden. Causes of death in Sweden 2009, 2011. Available from. http://www.socialstyrelsen.se/ publikationer2011/2011-3-22

18. Breslow NE, Day NE. Statistical methods in cancer research. Volume II--The design and analysis of cohort studies. IARC Sci Publ 1987:1-406.

19. Poulsen AH, Christensen S, McLaughlin JK, et al. Proton pump inhibitors and risk of gastric cancer: a population-based cohort study. Br J Cancer 2009;100:1503-7.

20. Sobin L, Wittekind C. International Union Against Cancer (UICC)Classification of malignant tumours. 6th edition, 2002.

21. Gurpinar E, Grizzle WE, Piazza GA. NSAIDs inhibit tumorigenesis, but how? Clin Cancer Res 2014;20:1104-13.

22. Ford AC. Chemoprevention for gastric cancer. Best Pract Res Clin Gastroenterol 2011;25:581-92.

23. Song H, Held M, Sandin S, et al. Increase in the Prevalence of Atrophic Gastritis Among Adults Age 35 to 44 Years Old in Northern Sweden Between 1990 and 2009. Clin Gastroenterol Hepatol 2015;13:1592-600.

24. Anderson WF, Camargo MC, Fraumeni JF, et al. Age-specific trends in incidence of noncardia gastric cancer in US adults. JAMA 2010;303:1723-8.

25. Pisanu A, Podda M, Cois A, et al. Gastric cancer in the young: is it a different clinical entity? A retrospective cohort study. Gastroenterol Res Pract 2014;2014:1-9.

26. Tavares A, Gandra A, Viveiros F, et al. Analysis of clinicopathologic characteristics and prognosis of gastric cancer in young and older patients. Pathol Oncol Res 2013;19:111-7.

27. Lamers $\mathrm{CB}$. The changing role of $\mathrm{H} 2$-receptor antagonists in acidrelated diseases. Eur J Gastroenterol Hepatol 1996;8 Suppl 1(Suppl 1):S3-S7.

28. Havu N. Enterochromaffin-like cell carcinoids of gastric mucosa in rats after life-long inhibition of gastric secretion. Digestion 1986;35(Suppl 1):42-55.

29. Poynter D, Pick CR, Harcourt RA, et al. Association of long lasting unsurmountable histamine $\mathrm{H} 2$ blockade and gastric carcinoid tumours in the rat. Gut 1985;26:1284-95.

30. Bakkelund K, Fossmark R, Nordrum I, et al. Signet ring cells in gastric carcinomas are derived from neuroendocrine cells. $J$ Histochem Cytochem 2006;54:615-21.

31. Waldum HL, Aase S, Kvetnoi I, et al. Neuroendocrine differentiation in human gastric carcinoma. Cancer 1998;83:435-44.

32. Ally MR, Veerappan GR, Maydonovitch CL, et al. Chronic proton pump inhibitor therapy associated with increased development of fundic gland polyps. Dig Dis Sci 2009;54:2617-22.

33. Engstrand L, Lindberg M. Helicobacter pylori and the gastric microbiota. Best Pract Res Clin Gastroenterol 2013;27:39-45. 